\title{
Speaking at Home
}

\author{
Jo Stuthridge
}

Psychotherapist in Private Practice, Dunedin

\begin{abstract}
This paper was originally presented as a short speech to the New Zealand Association of Psychotherapists' Annual Conference in Dunedin 2011. In it, I sketch three broad conclusions from developmental research and consider the implications for a relational approach to psychotherapy practice, from a transactional analyst's perspective. I use my experience of speaking at home to illustrate how ongoing development of the self is coconstructed through encounters with others.
\end{abstract}

I tukuna tuatahitia tēnei tuhinga hei kōrero poto i te Hui Wānanga à-Tau a te Rōpù Kaiwhakaora Hinengaro o Aotearoa o te tau 2011 i Otepoti. I reira, i whakaarahia ake ngā whakatau e toru puta ake i ngā rangahau whanake, ā, ka whakaaro ki ngā rara ki te whāia he huarahi hono ki te umanga kaiwhakaora hinengaro e ai ki tā te umanga kaitātari tirohanga. I whakamahia aku wheako kōrerorero i te kāinga hai whakaata i te whanaketanga o te kiriitau mai i te pānga atu ki ētahi.

Keywords: attachment; development; enactment; psychoanalysis; transactional analysis

\section{Home is Where we Start From}

Kia ora koutou. The main reason I was asked to speak today is that I live here. Dunedin is my home.

Speaking at home is terrifying. Standing here reminds me of Sunday evenings in childhood. After church, the roast dinner and an afternoon spent drinking, there was always singing and music. Mostly we played for grandad, hoping for a nod or a wink. Standing here feels like being in the front room of my grandparents' big state house performing for my parents, grandparents, 12 aunts and uncles and 22 cousins, many of whom were musicians. A voice whispers "Who does she think she is?", "She's got too big for her boots.” Actually I feel like the boots are too big for me. In projective fantasy I imagine your practised ears listening for a wrong note just as my father and grandfather once did. It seems that these internal voices derive from early relational experience and co-create new experiences in the present.

Stuthridge, J. (2012). Speaking at home. Ata: Journal of Psychotherapy Aotearoa New Zealand, 16(1), 33-41. DOI: 10.9791/ajpanz.2012.05. Copyright @ 2012 New Zealand Journal of Psychotherapists Inc. 
I'm a transactional analyst. Eric Berne (1910-1970), the founder of transactional analysis, was expelled from the San Francisco Psychoanalytic Institute for his efforts to present an interpersonal approach to psychoanalysis (Jorgensen \& Jorgensen, 1984). Transactional analysis, as the name implies, concerns the analysis of transactions. Recently there has been a strong turn toward the relational in psychotherapy, fuelled by an opening up of dialogue with other fields such as infant research and neuroscience. Since I began my training with my fourth baby in tow I have maintained a keen interest in developmental theory.

So standing here, quaking at home, I would like to offer a few thoughts from a transactional analyst, about how developmental research might inform a relational approach to clinical practise.

Relational theory assumes that humans are social beings and that development is primarily a relational process (Aron, 1996). We no longer think of the mind as an autonomous, isolated, disembodied entity - like a homunculus living in the skull. Cartesian assumptions that separated mind from body, thinking from feeling and self from other have dominated Western thinking for the past three hundred years. In recent decades, the "myth of the isolated mind" (Stolorow \& Atwood,1992) has been replaced by a view of the mind as embedded in relational, emotional and bodily experience. This idea is probably not new to Mãori, but from a European perspective, the discovery that development is not an individual process is a relatively new one - and sometimes referred to as a post-Cartesian perspective.

The developmental research points to three broad conclusions which have some major implications for psychotherapy. These conclusions are condensed from an earlier article (Stuthridge, 2010) and drawn from a wide range of writers who attempt to bridge the divide between empirical science and psychotherapy, in particular, Siegel (1999), Fonagy, Gergely, Jurist, \& Target (2002), and Wallin (2007).

\section{Three Conclusions from Developmental Research}

\section{The mind develops in co-created relationships}

Bowlby (1973) postulated that the everyday interaction between infants and caregivers is internalised to form internal working models which map the infant's expectations of a caregiver. Like Berne, Bowlby was unpopular with his peers, and had difficulty with acceptance from his country's analytic associations. His emphasis on the child's external environment was contrary to psychoanalytic thinking at the time, which asserted the primacy of intrapsychic processes in development. However Bowlby's work sparked a wealth of research in the field of attachment that has profoundly influenced contemporary psychotherapy. Developmental science and psychoanalysis have recently converged, to confirm many of Bowlby's insights.

Attachment researchers, neuroscientists and relational psychoanalysts use different concepts to explain how interpersonal experience is internalised to form the building blocks of the mind. Mitchell (1988, p.3) referred to "relational configurations within the mind”; Stern (1995) has referred to schemas-of-being-with and Lyons-Ruth (1998) has 
written about patterns of implicit relational knowing. Siegel (1999) described how interaction between infant and carer creates repeated patterns of neural firing or states of mind in the infant's brain. These theorists all agree that early relational experience shapes our internal world.

This core idea, that interpersonal experience structures the mind, is a foundational tenet of transactional analysis. Repeated transactions, such as touch and facial expressions, between an infant and caregiver are internalised to form a series of Child and Parent ego states or representations of self and other. These blueprints for relating create an unconscious relational pattern which is referred to as a script. Over a life time script unfolds, as "a dynamically progressive transference drama" (Berne, 1961, p. 174), and we tend to recruit others to play various parts in the drama. For example in this moment (i.e. during the original talk on which this article is based), I've enlisted you all en masse to play the part of a critical Parent introject, projecting my internal world, outside. With an audience that includes my supervisors, trainers, therapists and peers you are perfect for the part!

Thus unconscious script processes, including defence and conflict, develop through a complex interplay between intrapsychic and interpersonal realms, inside and outside. The idea that development occurs within a relationship suggests that therapeutic change also requires the involvement of two minds and, inevitably, two scripts. Healing requires a focus on co-created transactions between client and therapist.

\section{The mind is emotional and embodied}

The second broad conclusion the developmental research points to is that the mind is emotional and embodied. Script patterns are originally encoded in bodily rooted affect, not in cognitive or language systems. Neuroscience and infant research (Damasio, 1994; Fonagy, Gergely, Jurist, \& Target, 2002) have demolished the Cartesian split between mind and body, highlighting the importance of non-verbal communication, action and affect in development.

In the 1970 Mary Ainsworth, Bowlby's research assistant, established that attachment patterns are formed through non-verbal communication. She devised a procedure, called the "Infant Strange Situation", to observe attachment relationships between caregiver and child, which measures emotional and behavioural patterns (Ainsworth, Blehar, Waters, \& Wall, 1978). In adults, much of this experience remains unsymbolised but not repressed in the Freudian sense.

There is a reasonable consensus these days that attachment patterns are encoded in implicit memory, that is, in somatic, affective and sensorimotor systems (Cozolino, 2002; Siegel, 1999). This means that script patterns are experienced as sensations, feelings and behaviours, rather than as explicit memories. Implicit memory cannot be consciously recalled but it can be activated in the present, unconsciously influencing current perceptions of relationships. Research on implicit memory has helped elucidate the mechanisms behind transference and countertransference. For example, my embodied experience in the present (when giving the speech) - my jelly legs and shaky hands reveal more about my unconscious script than any explicit memories, like the scene in my grandparents' house. These physical sensations tell a wordless story about shame and 
exposure. Thus, explicit memories provide evidence which I can use to embellish, justify and make sense of the feeling.

Damasio's findings from neurobiology confirm the primacy of emotional bodily experience. In his book Descartes' Error (1994) Damasio presented a convincing argument that reason or thought is anchored in feelings. This is contrary to the idea with which most of us grew up: that thinking and feeling are separate functions. Damasio argued that cognition arises from gut feelings, which, in turn, depend on our ability to read bodily signals, and described the mind as a map of the body's changing landscape.

Recent trends in psychotherapy have paralleled findings in infant research and neurology with a shift in emphasis toward the primacy of affect in healthy development, motivation, pathology and healing relationships. Feelings have gained scientific kudos. The evidence suggests that therapists need to pay attention to non-verbal communication, including emotion and enactments, alongside verbal interaction.

\section{Coherent self-narrative in a parent predicts secure attachment in a child}

Mary Main, Ainsworth's student, developed the Adult Attachment Interview (Hesse, 1999). She expected to find that a parent with early secure attachment experiences would have securely attached children, but the results were a surprise. What was important was not the events or degree of trauma in a parent's childhood but, rather, the degree of coherence or incoherence in the narrative organisation of their stories. The results showed that how they told a story was more important than the content or the what. Why? It seems that the crucial factor which meditates an infant's attachment pattern is the parent's ability to develop a reflective coherent stance toward her own experience. Moreover, the parent's narrative pattern will actually predict the infant's attachment pattern with a rate of $75 \%$ accuracy even before the child is born (Fonagy, Steele, \& Steele, 1991; van IJzendoorn, 1995). Coherent self-narrative in a parent predicts secure attachment in a child. Likewise, incoherent narrative in a parent predicts insecure attachment in children (Fonagy, Steele, \& Steele, 1991).

This is a stunning finding with hopeful implications for psychotherapy. It suggests that coherence within the self may be key to preventing the intergenerational transmission of trauma. The evidence from longitudinal studies (Roisman, Padron, Sroufe, \& Egeland, 2002) shows that it is possible to develop coherence later in life. A secure relationship like marriage or long-term psychotherapy is the most common route to transformation (Siegel, 1999).

Peter Fonagy and his colleagues elaborated the attachment research, focusing on this capacity to reflect on experience, which they refer to as mentalising (Fonagy, Gergely, Jurist, \& Target, 2002). Mentalising is not a cognitive process, it concerns the capacity to understand feelings and read another's state of mind. A capacity to mentalise allows us to realise that our minds mediate our experience of the world, rather than simply equating feelings with reality. Fonagy and his colleagues argued that the evolutionary function of attachment behaviour is to provide an environment conducive to the development of mentalising. Their research has demonstrated that a capacity for this reflective functioning in a child depends on contingent attunement with a caregiver. Contrary to Cartesian doctrine, a coherent sense of self is not something with which we 
are born. It is a hard won developmental achievement. When a mother accurately mirrors and "marks" her infant's feelings, the infant integrates a representation of himself or herself as seen, felt and touched by their caregiver that is congruent with their bodily affect. The caregiver marks a feeling by showing the infant she or he understands the infant's distress, without being distressed themselves. The infant then develops a sense of himself or herself as sad, angry or lovable. Awareness of subjective mental states and an agentive self arises from this complex interpersonal process. As Winnicott (1967/1971) put it (I paraphrase): an infant discovers himself in his mother's eyes. The self as agent or subject, meaning the "I" who is aware of creating thoughts and feelings, is ultimately a social construction. Home is indeed where we start from.

\section{Summary - So far}

To summarise: the first principle concerns the crucial role of relationships in the developing mind; the second principle highlights the importance of affect and nonverbal patterns in development; and the third principle implies that the whole purpose of attachment is not to create a secure base, but rather to equip the child with a capacity to mentalise. It is this ability to reflect on our emotions, which enables us to liberate ourselves from repetitive relational patterns.

With contingent attunement a child develops a good ability to mentalise and integrate conflicting experiences into a complex self-narrative. From a transactional analysis perspective we can think of this capacity to integrate experience into self-narrative as a function of the Adult ego state (Stuthridge, 2006). Coherent self-narrative creates congruence and fluidity within the self, in the same way that an orchestra score creates harmony from a diverse range of instruments and notes, a metaphor which draws on similar images as those found in both Damasio's (1994) and Siegel's (1999) work.

When a child's experience of attunement is poor, the capacity to mentalise is compromised. The child develops an incoherent script and a disconnected sense of self. Having an incoherent script is a bit like living with discordant background music. A client who worked with film summed up this idea for me, when she said, "You can't change the events in the movie of your life, but you can change the background music."

Affective states that are not validated by an attachment figure remain unintegrated or "not me" (Bromberg, 1998; Sullivan, 1953). For example, when a parent shames a toddler who expresses hate or rage, these feelings form pockets of dissociated and dysregulated affect (Schore, 2009). Rather than being integrated into conscious self-narrative, this experience remains "unformulated" (Stern, 1983) or "unsymbolised" (Bucci, 1997) and unlinked from the subjective "I". Bromberg (2006) likened these dissociated experiences to snapshots that have not been put in an album. Experience that is not integrated into narrative has no voice or words. Instead, unsymbolised experiences are enacted in the present, creating repetitive transference patterns and script drama.

\section{Implications for Practice}

If the mind develops in relationships, it follows that a relational process in psychotherapy 
will foster ongoing development. It takes two. Attachment theory suggests that an intersubjective process is needed to enhance coherence within the self. Developmental research findings converge neatly with relational approaches to therapy at this point. Just as Bowlby insisted that the actual parents play a major role in a child's development, relational psychoanalysts (Aron, 1996; Benjamin, 1990; Hoffman, 1998/2001; Mitchell, 1988) have been insisting that the therapist's subjective participation is inevitable and will influence the outcome. I was trained to approach each session as a "blank page" and park my personal proclivities outside the door. Transactional analysis provided an interpersonal theory but the methods were grounded in a traditional "one person" (Stark,1999) approach. Berne advocated what he referred to as a "Martian" perspective while objectively analysing transferential dynamics. Relational and constructivist perspectives (Hoffman, 1998/2001; Mitchell, 1988) now argue that neutrality or objectivity in the therapist is a fallacy. A Martian stance is impossible. Relational psychoanalysts assume that the therapist's defences or script will become entangled with the client's, forming a series of co-created enactments. These repeated enactments are considered central to the work rather than failures, and thus the therapist's subjective experience becomes the primary vehicle for disentangling such dramas. As these impasses are resolved in the dyad, the client is freed from the shackles of script, to find new ways of being, feeling and relating. Psychotherapists have been divided in recent decades by a debate between the virtues of insight and empathy in technique. This debate has roots in Cartesian splits between thinking and feeling. An interpretative style tends to privilege the therapist's reality, through her or his focus on insight and intrapsychic processes. An empathic approach tends to privilege the client's reality, with a therapy that focuses on holding, attunement and relatedness. From a post-Cartesian perspective, however, empathy and insight are not at odds and, indeed, both are essential to transformation. Intersubjectivity requires, in addition, a willingness to grapple with the subjective realties of both client and therapist. Therapy invites repeated clashes between two subjects or, as Ehrenberg (1992) put it, an encounter at the "intimate edge". Relational analysts use a plethora of methods to resolve these human knots with an emphasis on authentic personal involvement.

The second principle, the idea that the mind is embodied, underscores the importance of attending to non-verbal experience. This idea implies a shift in focus from verbal and cognitive interaction to feelings, actions and bodily experiences. Wallin (2007) has said that this is like learning to listen to the music as distinct from the lyrics of a song. Wallin (2007) also suggested that the client who has no words for his experience, will embody it, enact it or evoke it in others through patterns of projective identification. Dissociated experiences are tossed about between client and therapist in an unconscious drama as we attempt to recruit the other for a role in our script. During a mutual enactment the unconscious relational patterns of both client and therapist intersect. Rather than remaining safely on Mars, the therapist accepts that she will be caught in the currents of countertransference and uses her emotional involvement to help locate her own and her client's dissociated self states. Enactments always carry the potential either to reinforce or transform a script. The outcome largely depends on the therapist's ability to mentalise and move out of the emotional grip of the entanglement. We often discover previously disowned parts of ourselves along the way. 
The third principle, drawing on the mentalisation research, points to the goal of therapy. The therapy relationship provides a fertile environment to increase the client's capacity for mentalising. The therapist's job is to help the client integrate dissociated experience through an emotionally responsive relationship. In Bromberg's (1998, p. 171) words, therapy is concerned with "the construction of a more inclusive reality". By gathering up the unwanted parts of self, the bits that have been embodied, enacted or projected, the client develops a more complex and coherent sense of self. We gain a broader capacity to contain conflict rather than acting it out with others. Instead of using the other as an object to be feared or controlled we can recognise others as a "like subject" (Benjamin, 1995), with feelings and thoughts different from our own. With an increased ability to mentalise, the client also develops a sense of herself as a human subject, as author of her experience. The client moves from enacting to reflecting, or from being an actor in her script to being the script writer.

\section{Home: Coherence, Continuity, and Complexity}

Speaking at home has provided an excellent opportunity to project and enact my own incompatible bits and pieces. When I started preparing this talk I had an anxious dream. My aunts, uncles and cousins all appeared out of the dark to form an immaculate brass band, with shiny instruments and shoes. They played with precision timing and in perfect harmony.

I hope that by taking a risk here, I may be able to co-create with you in this moment, a new way of being. Rather than marching to the beat of an old tune, my hope is to integrate some of these characters, to muddy their shoes a little and temper my fears about exposure.

T.S Eliot's (1940/1972) poem, “East Coker”, the second of his “Four Quartets”, beautifully describes this notion of maturity as a movement toward coherence and complexity within the self. The conference title, "Home is Where we Start From" is inspired by a line in a passage which reads (p. 203):

Home is where one starts from. As we grow older

The world becomes stranger, the pattern more complicated

Of dead and living. Not the intense moment

Isolated, with no before and after,

But a lifetime burning in every moment.

The last line, "A lifetime burning in every moment", powerfully evokes a feeling of continuity within the self. It conjures images of past hurt, loss and love burning in a vibrant present. Effective therapy aims to foster this inclusive process.

In parallel with this goal, my hope for our association is that we might build a home for practitioners that fosters inclusivity. Like any developmental process I think this requires an intimate encounter with alterity or otherness. It requires a willingness to engage with each other, to clash and untangle our co-created enactments. Just as our clients struggle to construct an identity that is capable of holding conflicting aspects of 


\section{SPEAKING AT HOME}

the self, we might construct a home for ourselves that can accept conflict, difference and ambiguity: a home with open doors and a broad roof.

Thank you. Nō reira kia ora koutou.

\section{References}

Ainsworth, M., Blehar, M., Waters, E., \& Wall, S. (1978). Patterns of attachment: A psychological study of the Strange Situation. Hillsdale, NJ: Erlbaum.

Aron, L. (1996). A meeting of minds: Mutuality in psychoanalysis. Hillsdale, NJ: The Analytic Press.

Benjamin, J. (1990). An outline of intersubjectivity: the development of recognition. Psychoanalytic Psychology, 7 (supp), 33-46.

Benjamin, J. (1995). Like subjects, love objects: Essays on recognition and sexual difference. New Haven, CT: Yale University Press.

Berne, E. (1961). Transactional analysis in psychotherapy. New York, NY: Grove Press.

Bowlby, B. (1973). Attachment and loss. Vol. 2. Separation: Anxiety and anger. New York, NY: Basic Books.

Bromberg, P. (1998). Standing in the spaces. Essays on clinical process, trauma and dissociation. Hillsdale, NJ: The Analytic Press.

Bromberg, P. (2006). Awakening the dreamer: Clinical journeys. Mahwah, NJ: The Analytic Press.

Bucci, W. (1997). Psychoanalysis and cognitive science: A multiple code theory. New York, NY: Guildford.

Cozolino, L. (2002). The neuroscience of psychotherapy. New York, NY: W. W. Norton \& Co.

Damasio, A. (1994). Descartes' error: Emotion, reason and the human brain. London, UK: Macmillan.

Ehrenberg, D. B. (1992). The intimate edge: Extending the reach of psychoanalytic interaction. New York, NY: W. W. Norton \& Co.

Eliot, T. S. (1972). East Coker. In Collected Poems 1909-1962 (pp. 196-204). London, UK: Faber \& Faber. (Original work published 1940)

Fonagy, P., Gergely, G., Jurist, E., \& Target, M. (2002). Affect regulation, mentalization, and the development of the self. New York, NY: Other Press.

Fonagy, P., Steele, H., \& Steele, M. (1991). Maternal representations of attachment during pregnancy predict the organization of infant-mother attachment at one year of age. Child Development, 62, 891-905.

Hesse, E. (1999). The adult attachment interview: Historical and current perspectives. In J. Cassidy \& P. Shaver (Eds.), Handbook of attachment: Theory, research and clinical applications (pp. 395-433). New York, NY: Guilford Press.

Hoffman, I.Z. (2001). Ritual and spontaneity in psychoanalytic process. Hillsdale, NJ: The Analytic Press. (Original work published 1998)

Jorgensen, E. W., \& Jorgensen, H. I. (1984). Eric Berne: Master gamesman. New York, NY: Grove Press.

Lyons-Ruth, K. (1998). Implicit relational knowing: Its role in development and psychoanalytic treatment. Infant Mental Health Journal, 19, 282-289.

Mitchell, S. (1988). Relational concepts in psychoanalysis. Cambridge, MA: Harvard University Press. 
Roisman, G. I., Padron, E., Sroufe, L. A., \& Egeland, B. (2002). Earned-secure attachment status in retrospect and prospect. Child Development, 73(4),1204-1219.

Schore, A. N. (2009). Right brain affect regulation: An essential mechanism of development, trauma, dissociation and psychotherapy. In D. Fosha, D. Siegel \& M. Solomon (Eds.), The healing power of emotion (pp.112-144). New York, NY: W. W. Norton \& Co.

Siegel, D. (1999). The developing mind. New York, NY: The Guilford Press.

Stark, M. (1999). Modes of therapeutic interaction. Northvale, NJ: Jason Aronson.

Stern, D. B. (1983). Unformulated experience: From familiar chaos to creative disorder. Contemporary Psychoanalysis, 19(1), 71-99.

Stern, D. N. (1995). The motherhood constellation: A unified view of parent-infant psychology. New York, NY: Basic Books.

Stolorow, R. D., \& Atwood, G. E. (1992). Contexts of being:The intersubjective foundations of psychological life. Hillsdale, NJ: Analytic Press.

Stuthridge, J. (2006). Inside out: A transactional analysis model of trauma. Transactional Analysis Journal, 36(4), 270-283.

Stuthridge, J. (2010). Script or scripture? In R. Erskine (Ed.), Life Scripts: A transactional analysis of unconscious relational patterns (pp. 77-100) London, UK: Karnac Books.

Sullivan, H. S. (1953). Conceptions of modern psychiatry. New York, NY: Norton.

van IJzendoorn, M. (1995). Adult attachment representations, parental responsiveness and infant attachment: A meta-analysis on the predictive validity of the Adult Attachment Interview. Psychological Bulletin, 117, 387-403.

Wallin, D. J. (2007). Attachment in psychotherapy. New York, NY: The Guilford Press.

Winnicott, D. (1971). Mirror role of mother and family in child development. Playing and reality (pp.111-118). London, UK: Tavistock. (Original work published 1967)

\section{Acknowledgement}

This article is a revised version of an invited keynote speech given on $11^{\text {th }}$ February 2011 at the Annual Conference of the New Zealand Association of Psychotherapists, held in Dunedin, $11^{\text {th }}-13^{\text {th }}$ February, 2011.

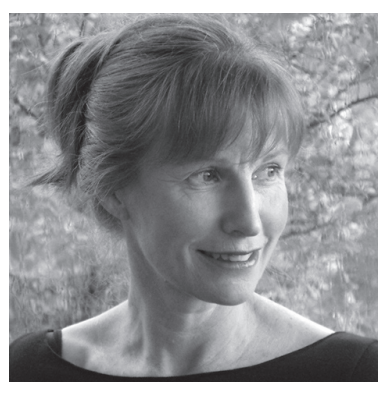

Transactional Analysis Journal (http://itaaworld.org/index.php/taj). Contact details: jstuthridge@xtra.co.nz

Jo Stuthridge, MSc, MNZAP is a Teaching and Supervising Transactional Analyst and a registered psychotherapist. She maintains a private psychotherapy practice in Dunedin, and is director of the Physis Institute, which provides training in transactional analysis. She has recently contributed chapters to Life Scripts: The Transactional Analysis of Unconscious Relational Patterns (Karnac Books, 2010) and also Relational Transactional Analysis: Principles in Practice (Karnac Books, 2011). She is a co-editor of the 